\title{
Edge detection and depth estimation of Galala El Bahariya Plateau, Eastern Desert-Egypt, from aeromagnetic data
}

\author{
Saada A. Saada
}

Received: 28 May 2015/ Accepted: 12 November 2015/Published online: 25 November 2015

(C) Springer International Publishing Switzerland 2015

\begin{abstract}
Edge detection and depth estimation techniques are very important step in the interpretation of magnetic anomalies. In this paper, the fast Fourier transform is applied to show the regional and residual sources. Different edge detection processes, for example, tilt angle derivative and its total horizontal derivative as well as 3D-Euler deconvolution, can determine the edges of these sources. These techniques were carried out on the aeromagnetic data of Galala El Bahariya Plateau. The estimated Euler solutions were plotted on the tilt angle derivative map. A good correlation was noticed between these techniques indicating that both of them can be attributed in delineating the general structural framework of the area. These techniques indicated that the Eastern part of Galala El Bahariya Plateau was highly affected by the Gulf of Suez rifting system. Whereas, the western parts of this plateau was slightly affected by the Gulf rifting system. Furthermore, the old Tethyan trend was maintained in both regional and residual components. The depth estimation was applied using analytic signal and Source Parameter imaging techniques. These depth methods show comparable results. The depth to the top of the basement sources ranges from 240 to about $4340 \mathrm{~m}$.
\end{abstract}

S. A. Saada ( $\square)$

Geology Department, Faculty of Science, Suez

University, Suez, Egypt

e-mail: saada_geo@yahoo.com
Keywords Galala $\cdot$ FFT · Edge detection - TDR · ED $\cdot$ AS and SPI

\section{Introduction}

Bournas and Baker (2001), Ardestani and Motavalli (2007) described edge detection of causative sources as one of the most important stages in the modeling of both magnetic and gravity anomalies. Several techniques have been involved to recognize edge detection, for example, Analytic signal (AS), tilt angle derivative (TDR), Euler Deconvolution (ED) etc. (Arisoy and Dikmen 2013). The potential field derivatives are largely used to model the buried sources (Arisoy and Dikmen 2013). Pilkington and Keating (2004), Cooper and Cowan (2008), Cooper (2009) and others used the AS to interpret and model both gravity and magnetic data.

The magnetic data are related to changes in magnetic susceptibilities and depths of their sources. Therefore, these data are used to determining the locations and the depths of the magnetic bodies that have been caused by them. This aim has recently become particularly important because of the abundance of magnetic data that was applied for reconnaissance explorations of minerals and petroleum. Different methods, based on the use of the magnetic field derivatives, have been developed to determine magnetic source parameters such as locations of 
boundaries and depths (Salem et al. 2008). Salako (2014) used Source Parameter Imaging (SPI) to determine the depth to basement surface.

In this paper, different derivative techniques (e.g., TDR and ED) have been applied on the Galala El Bahariya Plateau to locate the boundaries and the depths of the magnetic sources. It is interested to correlate between these edge detection methods to measure the degree of similarity between their results. AS and SPI are used to calculate the depth to basement of the study area. Correlation between them also should be notice.

\section{The study area}

Galala El Bahariya (Northern Galala) Plateau is a high flat topped plateau that lies between latitudes $28^{\circ} 50^{\prime} \mathrm{N}$ and $29^{\circ} 45^{\prime} \mathrm{N}$ and longitudes $31^{\circ} 40^{\prime} \mathrm{E}$ and $32^{\circ} 30^{\prime} \mathrm{E}$ and is one of the most impressive topographical features in the northern part of the north Eastern Desert. The area under investigation lies on the northern part of Egyptian Eastern Desert. It lies on the western side of the Gulf of Suez and covers a surface area of about $2500 \mathrm{~km}^{2}$ (Fig. 1). Nearly, it comprises most of Galala El Bahariya Plateau. The maximum height of this plateau is recorded in the study area $(2 \mathrm{~km}$ north to Bir Malha) of about $1272 \mathrm{~m}$ (above sea level). The field observations and topographic maps illustrate sharp topographic gradient running in the NW direction along the eastern side (west to the Gulf of Suez). In addition, another parallel sharper gradient in the same direction is noticed in the middle part east to Bir Malha, Bir Makhail, and Bir Maih areas. A NE sharp slope is displayed along Bir el Meisa and Bir Blkheit area (Fig. 1) in the southern part. This dip leads to Wadi Araba that separates the Northern and the Southern Galala Plateaus (Galala El Bahariya from Galala El Qibliya).

Galala El Bahariya was affected by tectonic movements, which took place during Late Cretaceous, Early Eocene, and Neogene. The dominating faults trend in the East-West direction, especially in the northernmost part of the plateau, but other trends e.g. NW-SE (Gulf of Suez) and NE-SW are common. Galala El Bahariya, like other localities in the northern part of the Eastern Desert, is affected by volcanic intrusions. Basaltic sheets can be seen at the top of the plateau, and at several opening of its valleys.
The complexity of the structure of the area is tightly related to the regional structures in the north Eastern Desert. According to Shalaby (1985), the main structural elements show three types primary, secondary structures, and dikes.

The first one includes the flow structure, Beading, lamination, Graded Bedding and unconformities. While the second one has a foliations, fracture cleavages, folds, joints and faults. The third type of structural elements, dikes, which cuts the area. These dikes include three types, acidic, intermediate, and finally basic dikes.

Folding plays a minor role in controlling the structural pattern of the western Gulf of Suez area (eastern part of Galala El Bahariya). Most of the noticed folds were produced either by bending of the strata before breaking or by movements that caused the less rigid sediments, especially the Miocene sediments, to bend in anticlinal or synclinal folds (Said 1962).

\section{Data source}

Aeromagnetic surveys in Egypt flown in the 1983. The magnetic data was digitized from total intensity aeromagnetic map with scale of 1:50,000 after the Egyptian General Petroleum Corporation (EGPC 1983). It was surveyed at a flight direction of $45 / 225^{\circ}$ and tie $135 / 315^{\circ}$, flight altitude $120 \mathrm{~m}$ terrain clearance, flight interval $1.5 \mathrm{~km}$ traverse and tie $10 \mathrm{~km}$, inclination angle $39.5^{\circ} \mathrm{N}$ and declination angle of $2^{\circ} \mathrm{E}$, the total magnetic intensity $42,425 \mathrm{nT}$ and contour interval of $2 \mathrm{nT}$. The total intensity aeromagnetic map is shown in Fig. 2. The reduced to pole (RTP) map (Fig. 3) is constructed using Geosoft (Oasis Montaj) Program (2007). This step is applied to correct the position of the magnetic anomalies directly above their true sources.

\section{Methodology}

4.1 Regional-residual separation using the fast Fourier transform (FFT)

The FFT was applied on the magnetic data for calculating the energy spectrum curves and estimating the residual (shallow) and regional (deep) sources. 


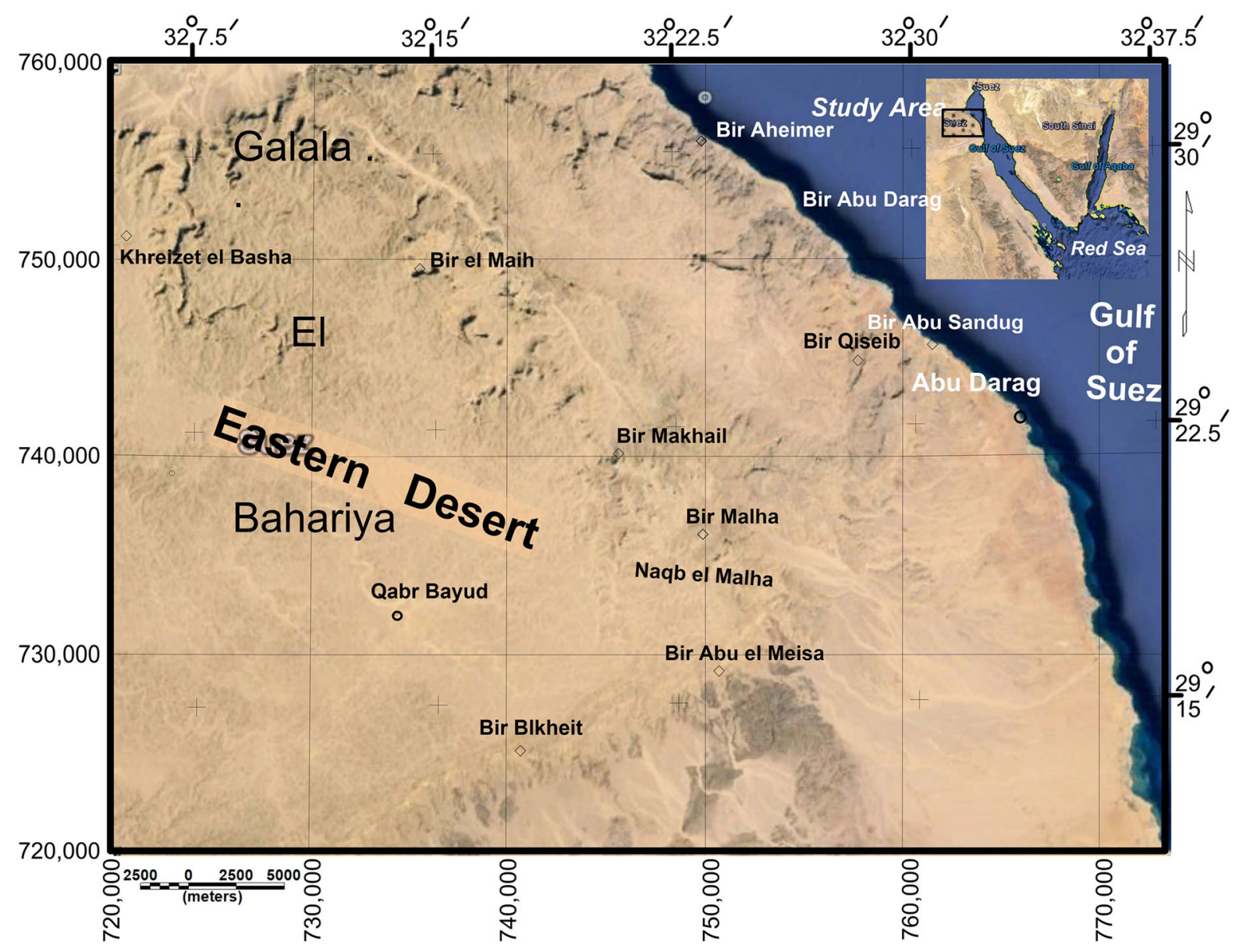

Fig. 1 Location map of Galala El Bahariya Plateau

This filter is based on the cut-off frequencies that pass or reject certain frequency values and pass or reject a definite frequency band.

Radially averaged power spectrum method is used to determine the depths of volcanic intrusions, depths of the basement complex and the subsurface geological structures. Several authors, such as Bhattacharya (1966), Spector and Grant (1970) explained the spectral analysis technique. It depends on the analysis of the magnetic data using the Fourier Transform. It is a function of wavelengths in both the $\mathrm{X}$ and $\mathrm{Y}$ directions. The grid is processed to become periodic on its edges. The Fourier transform $f(\mu, \mathrm{y})$ of periodic function $f(\mathrm{x}, \mathrm{y})$ is given by Lee (1960) as:

$f(\mu, \gamma)=\int_{-\infty}^{+\infty} \int_{-\infty}^{+\infty} f(\mathrm{x}, \mathrm{y}) \cdot \mathrm{e}^{-i(\mu \mathrm{x}+\gamma \mathrm{y})} \mathrm{dx} \cdot \mathrm{dy}$ where ( $\mathrm{x}$ ) and (y) are the spatial coordinates in the $\mathrm{x}$ and $y$ directions respectively. $\gamma$ and $\mu$ are the angular frequencies in the $\mathrm{x}$ and $\mathrm{y}$ directions respectively.

\subsection{Edge detection methods}

\subsubsection{The tilt angle derivative (TDR) and its total horizontal derivative (THDR_TDR)}

TDR and THDR_TDR are used for mapping shallow basement structures and mineral exploration targets (Geosoft Program 2007). TDR is used for enhancing features and causative body edge detection in potential field images. Miller and Singh (1994), Verduzco et al. (2004) suggested the tilt angle filter. It was developed later by others such as Salem et al. $(2007,2008)$ and Fairhead et al. (2008). It showed a considerable 


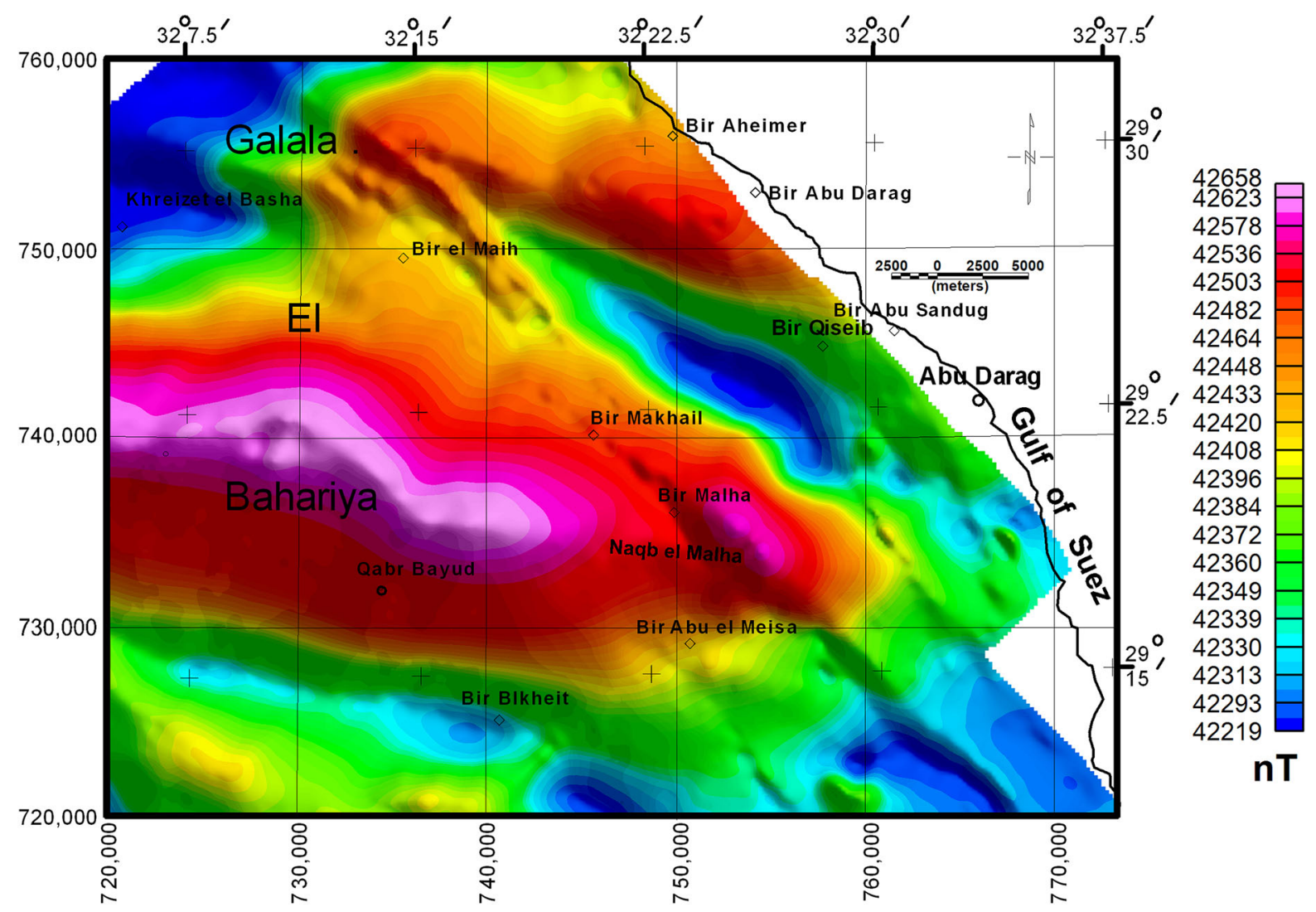

Fig. 2 Shaded color total intensity aeromagnetic map of the Galala El Bahariya (Northern Galala) plateau

interest because of its fundamental and practical simplicity (Hinze et al. 2013). This filter is defined as:

$$
T \mathrm{DR}=\tan ^{-1}(V D R / T H D R)
$$

where VDR is the vertical derivative and THDR is the total horizontal derivatives.

i.e.: $\quad T \mathrm{DR}=\tan ^{-1}\left(\frac{\partial f / \partial z}{\sqrt{(\partial f / \partial x)^{2}+(\partial f / \partial y)^{2}}}\right)$

where $f$ is the magnetic or gravity field, while $\delta f / \delta \mathrm{x}, \delta f /$ $\delta y$ and $\delta f / \delta z$ are the first derivatives of the field $f$ in the $\mathrm{x}, \mathrm{y}$ and $\mathrm{z}$ directions, respectively. The amplitudes of TDR range between $-\pi / 2$ and $+\pi / 2$ (radian) or $-90^{\circ}$ to $90^{\circ}$ regardless of the amplitude of the vertical derivative or the absolute value of the total horizontal gradient (Salem et al. 2008). The TDR produces a zero value over or close to the source edges and, therefore, can be used to trace the outline of the edges (Miller and Singh 1994). Positive values are located directly above the sources while negative values are located away from them. Furthermore, the horizontal distance from the $45^{\circ}$ to the $0^{\circ}$ position of the tilt angle is equal to the depth to the top of the contact (Hinze et al. 2013) or the half distances between $-45^{\circ}$ and $+45^{\circ}$ (Salem et al. 2007).

THDR_TDR is the square root of the sum of the squares derivatives of the tilt angle in the $\mathrm{x}$ and $\mathrm{y}$ directions.

THDR of $T \mathrm{DR}=\sqrt{\left(\frac{\partial T D R}{\partial X}\right)^{2}+\left(\frac{\partial T D R}{\partial Y}\right)^{2}}$

THDR_TDR is not depend on inclination, similar to AS. The difference between these derivatives is that the former is sharper and generates better-defined maxima centered over the body edges. Another advantage of this independence, that it will generate useful magnetic responses for bodies having induced or remanent magnetization, or a mixture of both (Rahman and Ullah 2013). 


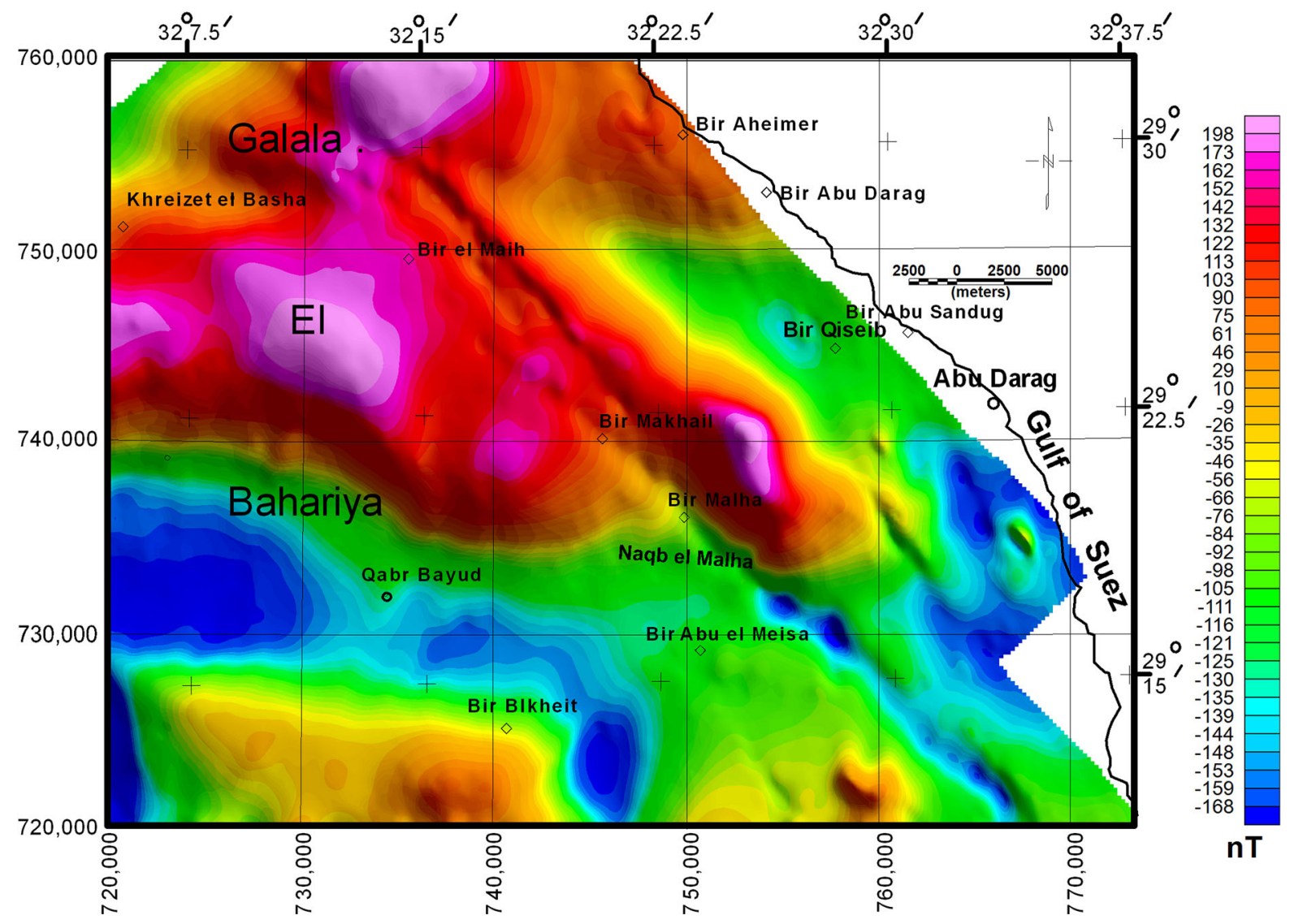

Fig. 3 Shaded color RTP aeromagnetic map of the Galala El Bahariya Plateau

\subsubsection{D-Euler deconvolution (ED)}

Recently, use of Euler Deconvolution (ED) has become more widespread because it has been automated and rapid interpretation. It works with either profile or grid data (Reid et al. 1990; Klingele et al. 1991; Marason and Klingele 1993; Harris et al. 1996; Stavrev 1997; Barbosa et al. 1999).

It requires three orthogonal gradients (two horizontal and vertical gradients) of the magnetic or gravity data, which (if they have not been measured) are normally, calculated using FFT. Hence, it is normally applied to gridded data, where the datasampling interval is uniform. It passes a moving window through the data, and uses least-squares inversion to obtain the depth and horizontal location of sources with different structural indices. ED technique was introduced in the potential field data to estimate the position of structural lineament. In this technique, no prior source magnetization direction required and does not affect by the presence of remanence (Ravat 1996). Usually the structural index (SI) is fixed and the locations and depths $\left(\mathrm{x}_{0}, \mathrm{y}_{0}, \mathrm{z}_{0}\right)$ of any sources are found using the following equation:

$\frac{\partial f}{\partial x}\left(x-x_{0}\right)+\frac{\partial f}{\partial y}\left(y-y_{0}\right)+\frac{\partial f}{\partial z}\left(z-z_{0}\right)=\operatorname{SI}(B-f)$

where $f$ is the observed field at location ( $\mathrm{x}, \mathrm{y}, \mathrm{z})$ and $\mathrm{B}$ is the base level of the field [regional value at the point $(\mathrm{x}, \mathrm{y}, \mathrm{z})]$ and SI is the structural index or degree of homogeneity (Reid et al. 1990). Equation (5) is solved for the source position by least-squares inversion of a moving window of data points. To obtain an accurate estimate of the source location, the field data used must adequately sample the anomalies present in the data.

Accordingly, ED requires four sets of grids as input data; the total magnetic field, first horizontal 
derivative in $\mathrm{x}, \mathrm{y}$ and vertical derivative in $\mathrm{z}$-direction. It is insensitive to magnetic inclination and declination. Therefore, the north-south extending geologic features reflect a low signal to noise ratio in the data and therefore, reduction to the pole data can be applied to improve this situation (Durrheim and Cooper 1998). The size of window should be chosen large enough to incorporate substantial variation of the field gradients and it should be small enough not to include significant effects from multiple sources. i.e. The board anomalies arising from deep sources are poorly represented in small windows and vice versa. The quality of depth estimation depends on the choice of the correct structural index and adequate sampling of data. Therefore, the choice of the SI and electing of optimum criteria for selecting solutions are fundamental requirements for successful application of this method.

\subsection{Depth to basement estimation}

\subsubsection{Analytic signal (total gradient) method}

The analytic signal (AS) is the square root of the sum of the squares of the derivatives in the $\mathrm{x}, \mathrm{y}$ and $\mathrm{z}$ directions.

$$
\mathrm{AS}=\sqrt{\left(\frac{\partial f}{\partial X}\right)^{2}+\left(\frac{\partial f}{\partial Y}\right)^{2}+\left(\frac{\partial f}{\partial z}\right)^{2}}
$$

where $\frac{\partial f}{\partial x}, \frac{\partial f}{\partial y}$ and $\frac{\partial f}{\partial z}$ are the first derivative of the total magnetic field. It is very useful in locating the edges of magnetic source bodies (Geosoft (Oasis Montaj) Program 2007). The advantage of using AS technique to determine magnetic parameters from magnetic anomalies is the independence of magnetization direction (inclination). A drawback of this method, however, is the assumption that step models can characterize near-surface structures adequately. To improve mapping resolution, the amplitude ratio method has been extended to comprise both step-like and dike-like structures. A criterion is constructed to discriminate between maxima from dike-like or steplike structures and significantly improves near-surface structural mapping. This avoids a bias in geological interpretation caused by the original assumption that step models can characterize all structures (Roest et al. 1992; Mocloed 1993; Hsu et al. 1998).
The success of the AS method results comes from the fact that the location and depth of magnetic sources are found with only a few assumptions about the nature of the source body, which is usually assumed as 2D magnetic source (for example, step, contact, horizontal cylinder or dike). For these geological models, the shape of the amplitude of the AS is a bellshaped symmetric function located directly above the source body. The magnetic sources depths using the magnetic method are estimated from the ratio of the total magnetic AS to the vertical derivative analytic signal (AS1) of the total magnetic field.

$\mathrm{AS} 1=\sqrt{\left(\frac{\partial f v}{\partial X}\right)^{2}+\left(\frac{\partial f v}{\partial Y}\right)^{2}+\left(\frac{\partial f v}{\partial z}\right)^{2}}$

On the maximum amplitude

$\mathrm{D}=\frac{\mathrm{AS}}{\mathrm{AS} 1} \times N$

where $f v$ is the first vertical derivative of the total magnetic field, and D is the depth to the magnetic body, $\mathrm{N}$ is known as a structural index and is related to the geometry of the magnetic source. For example, $\mathrm{N}=4$ for sphere, $\mathrm{N}=3$ for pipe, $\mathrm{N}=2$ for thin dike and $\mathrm{N}=1$ for magnetic contact (Reid et al. 1990).

\subsubsection{Source parameter imaging (SPI) technique (local wavenumber technique)}

SPI is a technique based on the extension of complex AS to estimate magnetic depths; it is also known as local wavenumber. The original SPI method (Thurston and Smith 1997) works for two models: a 2-D sloping contact or a 2-D dipping thin sheet. For the magnetic field $f$, the local wavenumber is given by Eq. (9):

$k=\frac{\frac{\partial^{2} f}{\partial x \partial z} \frac{\partial f}{\partial x}-\frac{\partial^{2} f}{\partial x^{2}} \frac{\partial f}{\partial z}}{\left(\frac{\partial f}{\partial x}\right)^{2}+\left(\frac{\partial f}{\partial z}\right)^{2}}$

For the dipping contact, the maxima of $\mathrm{k}$ are located directly over the isolated contact edges and are independent of the magnetic inclination, declination, dip, strike and any remnant magnetization. The depth is estimated at the source edge from the reciprocal of the local wave number.

$\operatorname{Depth}_{(x=0)}=\frac{1}{k_{\max }}$ 


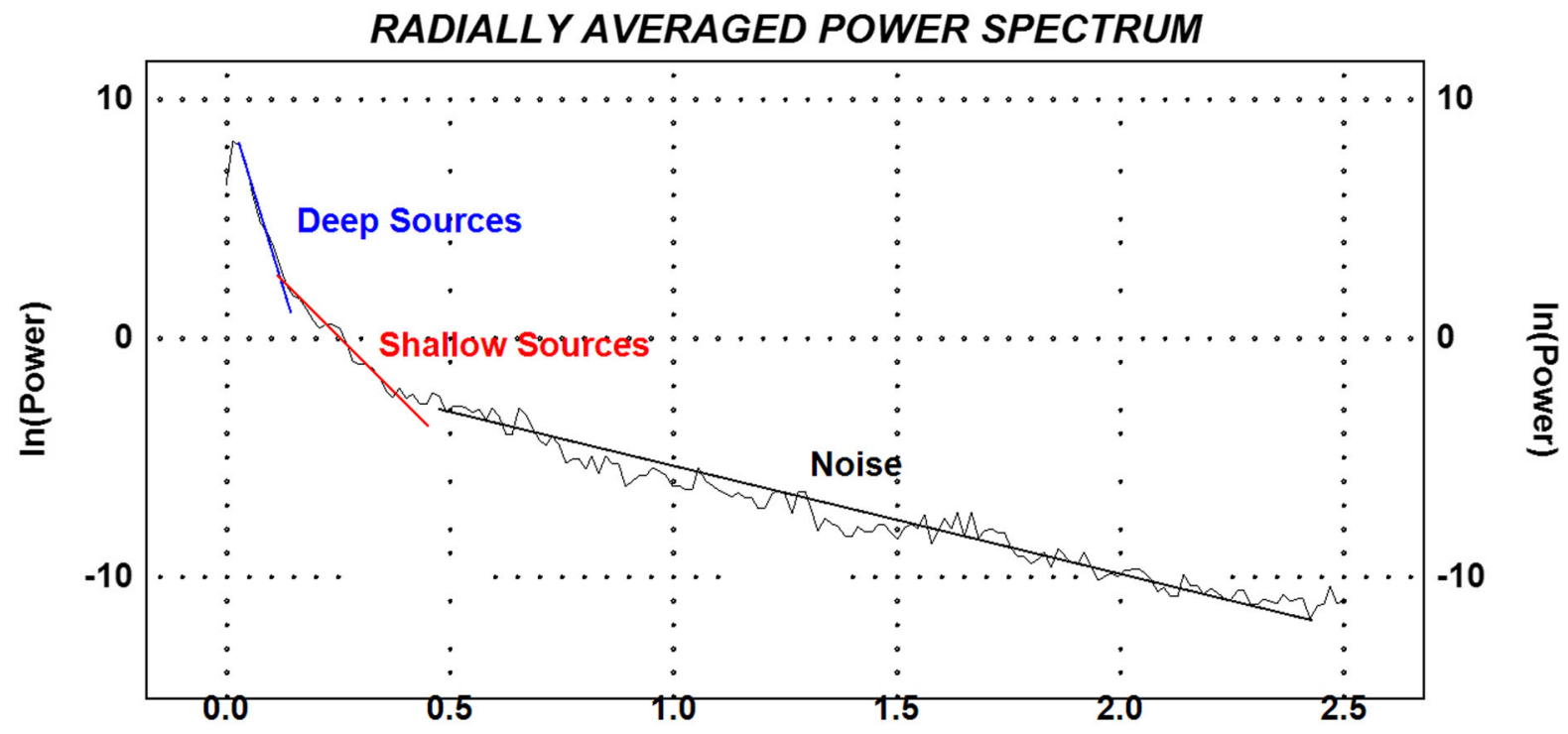

DEPTH ESTIMATE

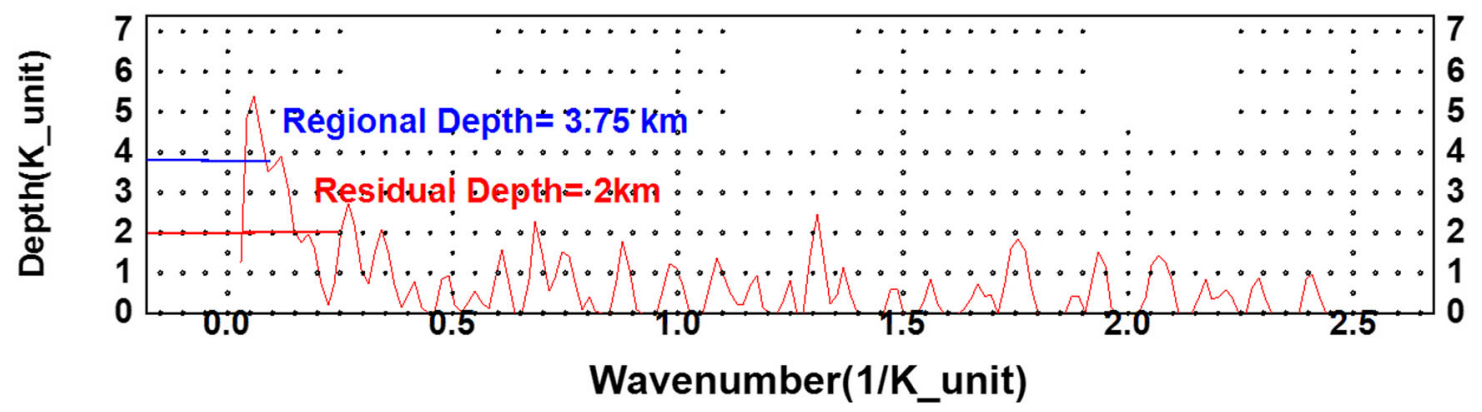

Fig. 4 Power spectrum of aeromagnetic data showing the corresponding averaging regional and residual depths, Galala El Bahariya Plateau

where $\mathrm{K}_{\max }$ is the peak value of the local of number $\mathrm{K}$ over the step source.

One more advantage of this method is that the interference of anomaly features is reducible, since the method uses the second-order derivatives. The SPI computes source parameters from gridded magnetic data. Solution grids show the edge locations, depths, dips, and susceptibility contrasts. The estimation of the depth is independent of the magnetic inclination, declination, dip, strike and any remanent magnetization (Thurston and Smith 1997).

In practice, the method is used on gridded data by first estimating the direction at each grid point. The vertical gradient is computed in the frequency domain, and the horizontal derivatives are computed in the direction perpendicular to the strike using the leastsquares method.

\section{Results and discussion}

The shaded relief of the total intensity aeromagnetic map (Fig. 2) shows high positive anomaly in the middle part trending in the E-W direction. The eastern part shows an elongated negative anomaly striking in a NW direction parallel to the Gulf of Suez coastline with sharp gradient. This sharp gradient is associated with faults. The maximum magnitude $(42,658 \mathrm{nT})$ is 


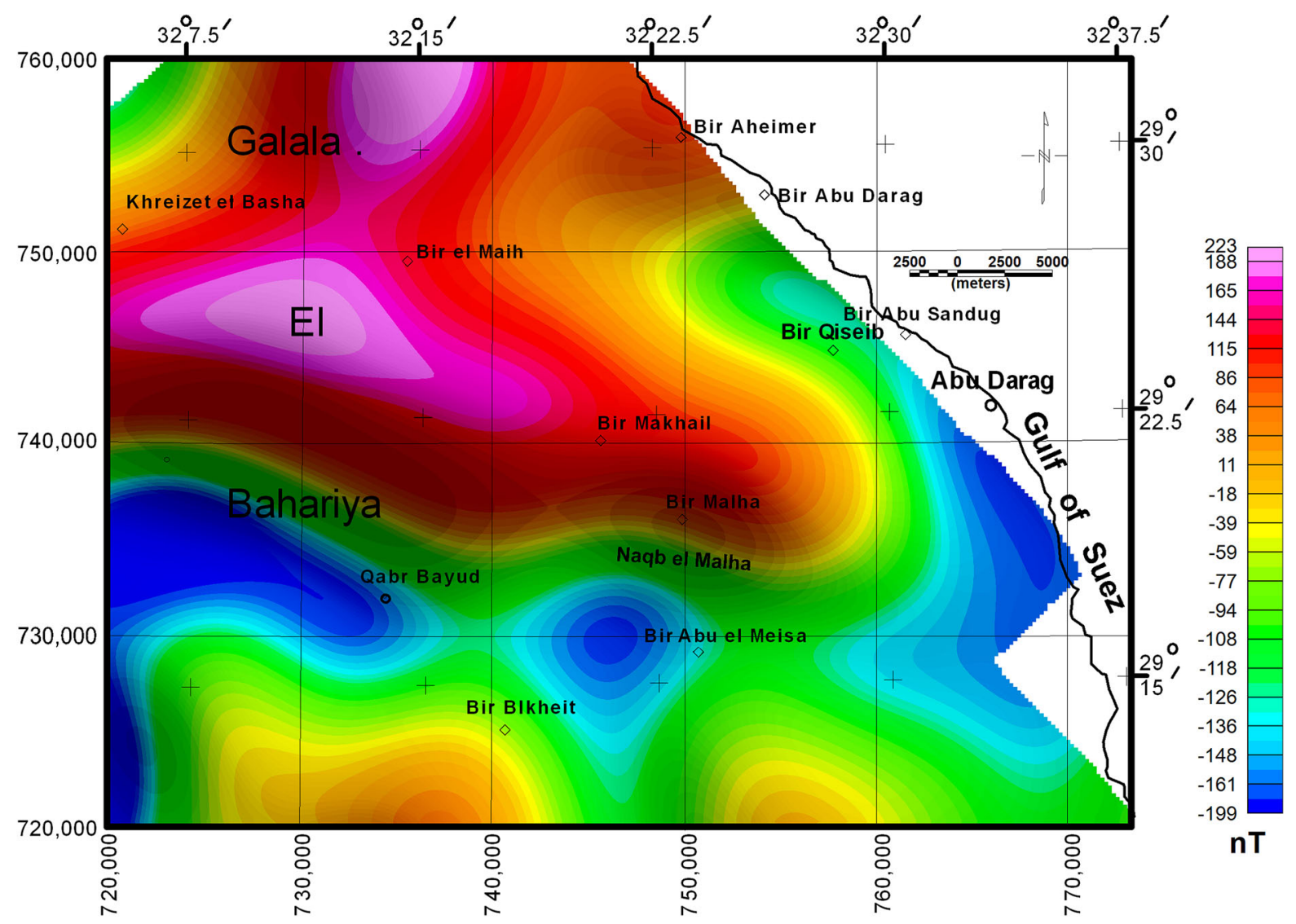

Fig. 5 Shaded color map of the RTP regional magnetic-component, Galala El Bahariya Plateau

recorded in the middle part north to Qabr Bayud may be due to uplifted basement block and/or related to intermediate or even basic dikes.

The RTP map shows that the main positive and negative anomalies are shifted to the north. The maximum positive anomaly with a magnitude of $261 \mathrm{nT}$ (after removing the main field of $42,425 \mathrm{nT}$ ) is located close to the northwest corners. Sharp linear anomalies with small extension can be observed running from the southeastern to the northwestern corners. This shows a good coincidence with the sharp topographic gradient that can be due to the NW Gulf of Suez faulting system. An E-W (Tethyan) trend is observed in southwestern corner of alternative negative (west to Qabr Bayud) and positive (along Bir Blkheit) anomalies with high gradient can be interpreted because of block faulting, which forms Wadi Araba. Generally, the RTP magnetic map is used for carrying out all different analytical techniques.
The average power spectrum (Fig. 4) for the RTP aeromagnetic data of the study area is applied using Geosoft (Oasis Montaj) Program (2007). This Figure indicates that the depth to the source bottom is recorded where a maximum peak is represented (Hinze et al. 2013). The bottom depth can be determined by forward modeling of the spectral peak (Ross et al. 2006; Ravat et al. 2007). From the power spectrum curve the regional and residual as well as noise signals are determined. The corresponding depth estimation chart is used to calculate the average depths to the top of these deep and shallow sources. The calculated average depth to the top of regional sources is about $3.75 \mathrm{~km}$ whereas the shallow sources have about $2 \mathrm{~km}$ average depth to their sources (Fig. 4).

According to this chart a low- and high-passes maps are constructed. The low-pass map (Fig. 5) is constructed with a cut-off wavelength of $12,400 \mathrm{~m}$ (wvaenumber 0.0806 1/k_unit). It shows an E-W 


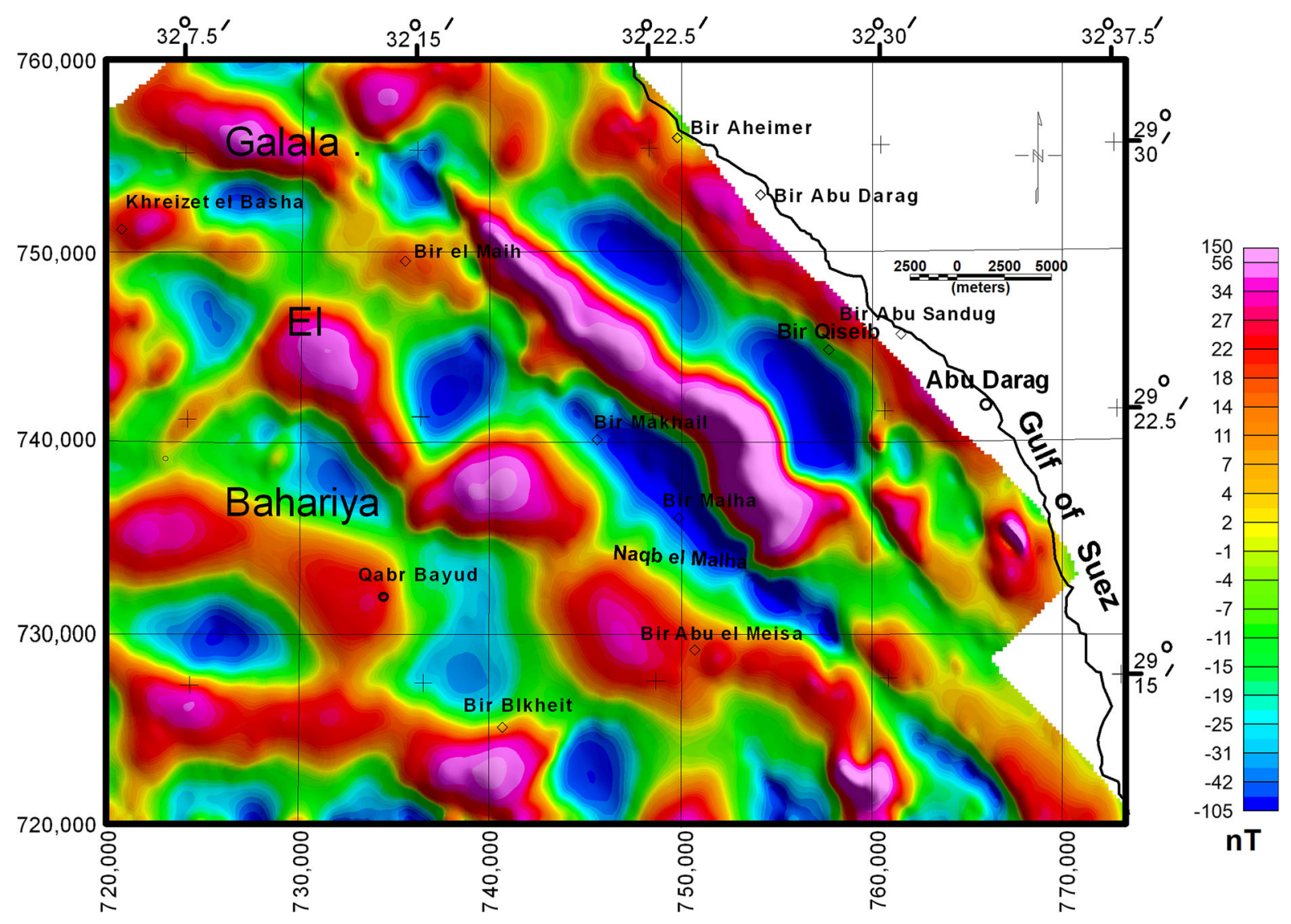

Fig. 6 Shaded color map of the RTP residual magnetic-component, Galala El Bahariya Plateau

(Tethyan-Mediterranean) trend affecting the deeper sources. Whereas, the high-pass filtered map (Fig. 6) exhibits a NW (Gulf of Suez) main trend allover the area except for the southwestern corner, which shows an E-W trend. On this map, we can see alternative closed elongated positive and negative anomalies have a NW trend. From the regional and residual maps we can conclude that the older E-W trend was intersected by the younger NW trend (Meshref et al. 1980). The eastern and northeastern parts of Galala El Bahariya along the Gulf of Suez were affected by the Gulf of Suez Rifting system during Miocene. The NW faults (oriented parallel to the Gulf of Suez coastline) of the northeastern edge of the Galala El Bahariya Plateau are also aligned with major basement lineaments and may have exploited preexisting basement structures during the rifting time (Moustafa and El Shaarawy 1987).

The TDR analysis of Miler and Singh, 1994 (Fig. 7) exhibits the geologic features like faults, which are depicted as magnetic lineaments. This method facilitates the horizontal location with extent of edges. It is suggested that the zero contour line (the bold black line) in the TDR map is the location of abrupt changes in magnetic susceptibilities between positive and negative anomalies that is particularly at the sharp gradient. Therefore, the zero contour line represents the contact boundary of magnetic sources. Zero contours can be identified as light yellow color which is separating the green color (negative values) and red colors (positive values) can be seen from the color scale bar (Fig. 7). On other hand, positive values are located directly above these magnetic sources while negative ones are located away from them. The TDR of RTP field data shows a NW lineament trend along eastern part of the study area with large coincident with topographic gradient. It shows an E-W trend in western and southern parts toward Wadi Araba that has an E-W trend.

According to the TDR map, we can conclude that the structure pattern of the eastern parts of Galala El 


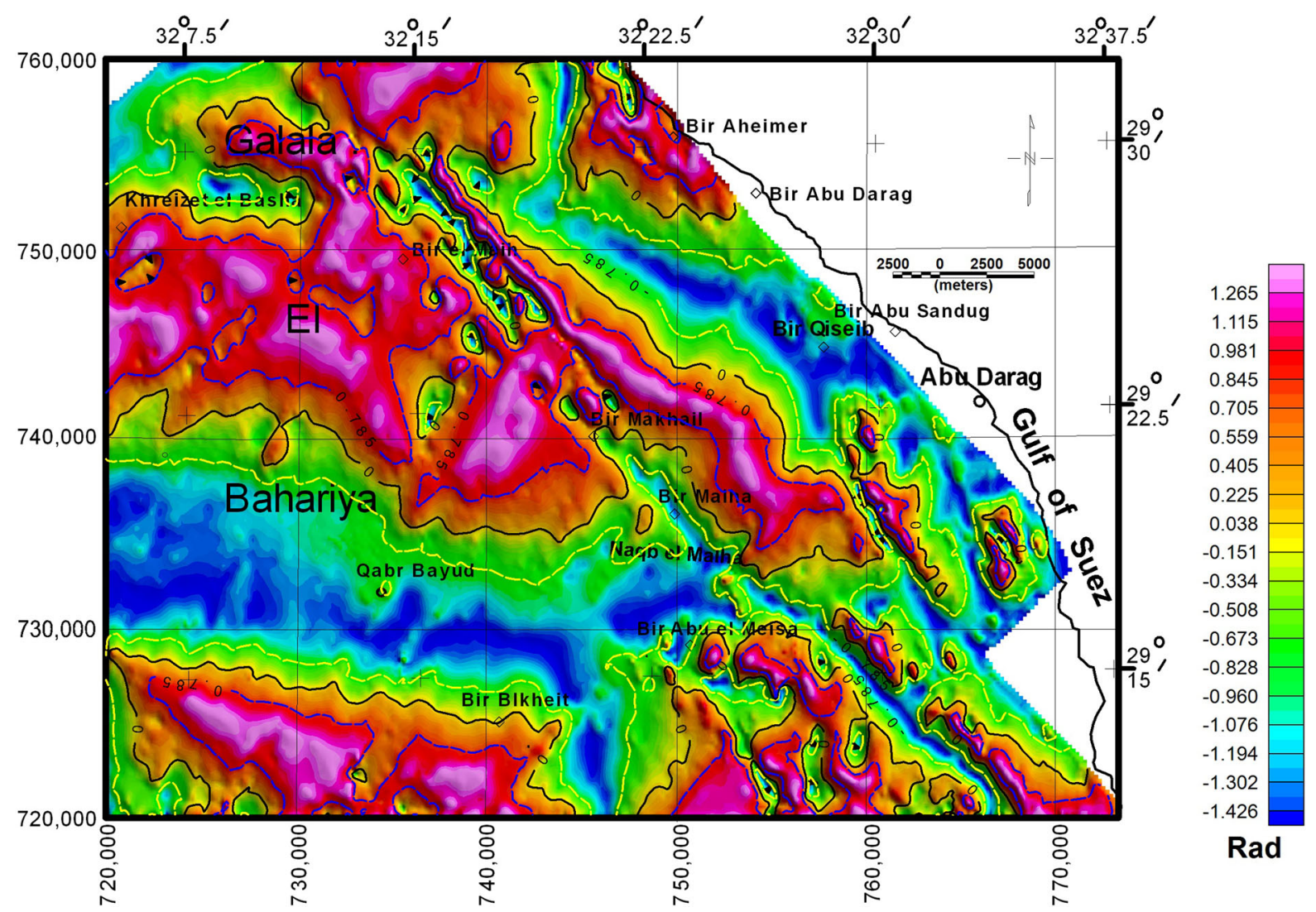

Fig. 7 Shaded color map of the TDR. The black bold lines show the 0 radian contour of the tilt angle. Galala El Bahariya Plateau

Bahariya Plateau along the Gulf of Suez was affected the Gulf of Suez and Red Sea rifting system. On other hand, the western and the southern parts away from the Gulf of Suez were less affected and still preserve the older E-W (Tethyan or Mediterranean) trend in their basement rocks. Both the NW and the E-W trends form uplifted and down faulted blocks where alternative positive and negative elongated anomalies are represented.

Salem et al. (2007) have shown that half-distance between $\pm 45^{\circ}$ contours provide an estimate of the source depth for vertical contacts. Oruc (2010) also used the half distance between $\pm \pi / 4$ Radians $\left( \pm 45^{\circ}\right)$ contours to estimate the depths of the edges of the uplifts. $-\pi / 4$ and $+\pi / 4$ Radians is remarked by yellow and blue dashed line, respectively (Fig. 7). By applying Salem et al. (2007) and Oruc (2010) methods, the depth to the uplifted blocks of the study area ranges from few hundreds of meters in the southeastern corner to more than 3000 m north to Qabr Bayud area.
Figure 8 shows the THDR of the TDR (Fig. 7). The THDR_TDR preserves the amplitude enhancement by its ability to define edges of well-defined maxima. Nearly, all the defined edges have a NW trend allover the area especially in the eastern parts (Fig. 8).

Since the amplitude of the THDR_TDR is related to the reciprocal of the depth to the top of the source (Rajaram 2009). The tilt angle overcomes the problem of the shallow and deep sources by dealing with the ratio of the vertical derivative to the horizontal derivative; the tilt derivative will be relatively insensitive to the depth of the source and should resolve shallow and deep sources equally well. However, from Fig. 8 and its colored bar scale, the depth to the top of the sources ranges from 500 to about $3850 \mathrm{~m}$ allover the area except for dark blue area in the western part where its depth exceeds this value.

Euler depth solutions map is shown in Fig. 9. The ED technique is applied on the RTP aeromagnetic data of Galala El Bahariya Plateau. The window size used 


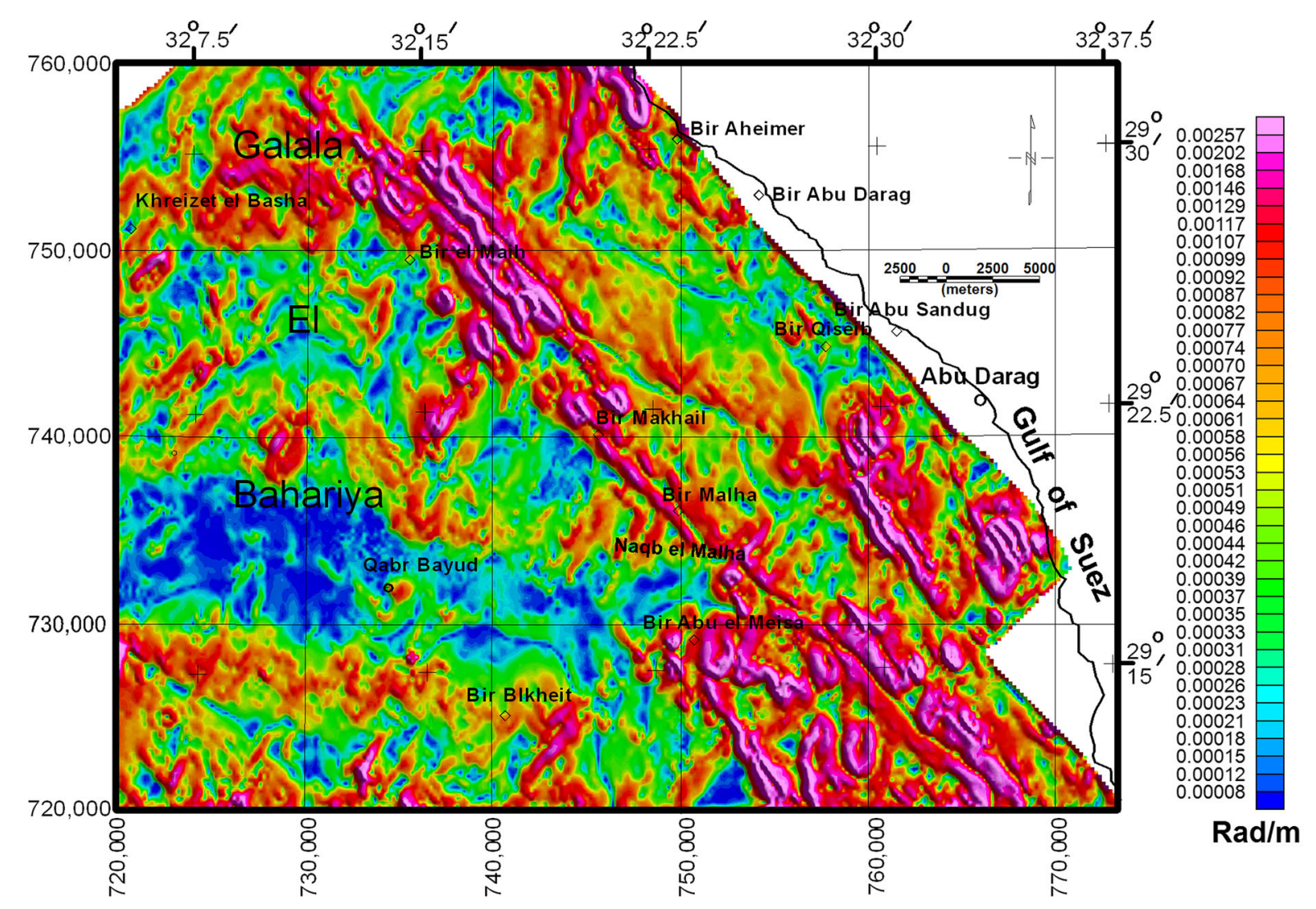

Fig. 8 Shaded color THDR_TDR map Galala El Bahariya Plateau

is $15 \times 15$ (grid cell size $=300 \mathrm{~m}$ ) with a maximum depth tolerance of $15 \%$. The structural index used is 0 to locate and determine the contact depth. The calculated depths solutions range from 285 to $2870 \mathrm{~m}$. The resulted solutions are plotted on the TDR map as shown in Fig. 9 to measure the degree of similarity between them. The main trends of ED solutions are NW and E-W as well as NNE (Aqaba trend) in few parts. The focusing of solution points seems as structural lineaments with these defined trends.

Under the assumption that the edges of anomalous sources are caused by vertical contacts, a very good correlation also is shown between Euler solutions locations for magnetic contact and the TDR zero line. Therefore, both the TDR and ED techniques are good edge (contact) detector and very well correlated among each other for aeromagnetic data.

The basement depth calculations are carried out in the study area by using the AS and source parameter imaging. The AS was applied on the RTP aeromagnetic data of Galala El Bahariya Plateau (Fig. 10a). It shows the edges locations of the magnetic sources in both horizontal and vertical dimensions. The first vertical derivative (Fig. 10b) shows alternative positive and negative anomalies trending in the NW direction at the eastern portion of the area with sharp gradient. The positions and trends of these anomalies are similar to those of the TDR map (Fig. 8). In the AS of the first vertical derivative map (Fig. 10c), the NW (Gulf of Suez) trend has the maximum amplitudes. These maxima are coincidence with the maximum topographic dip as illustrated from topographic map of the Galala El Bahariya Plateau.

According to Eq. (8), The AS of the RTP aeromagnetic map (Fig. 10a) is divided by the AS1 map (Fig. 10c) in order to construct the depth to basement contact of the area (Fig. 10d). Generally, the depth ranges from $242 \mathrm{~m}$ to in the eastern part to about $4340 \mathrm{~m}$ west to Qabr Bayud area at the western part. The calculated shallow depths allover Galala El Bahariya Plateau can be related to the volcanic 
intrusions and/or dikes, which are seen on the top of the plateau.

The SPI depth map (Fig. 11) shows great similarity to the depth map constructed by using AS technique. However, the depth ranges from about $300 \mathrm{~m}$ in the eastern area parallel to the Gulf of Suez coastline to about $4145 \mathrm{~m}$ in western part parallel to Wadi Araba to the south.

Finally, integration of TDR and ED techniques combined with FFT technique to locate the edge of the magnetic bodies and to estimate the depth of these bodies is feasible. The FFT was applied to separate the regional and the residual sources. Therefore, the locations, trends, and extensions for both regional and residual magnetic sources can be identified. The TDR and ED techniques can determine the locations and depths of these regional and residual sources. Therefore, the magnetic sources can be delineated and confirmed by these techniques. AS and SPI techniques were applied to calculate the depth to magnetic
Fig. 10 a Analytic signal, b first vertical derivative and c analytic signal of first vertical derivative shaded color maps used to calculate, $\mathbf{d}$ basement depth map using analytic signal method

sources and gave similar results. There is an obvious disadvantage when applying these derivative techniques because they have relatively higher levels of noise than the original field due to the high-pass effects. Therefore, it is recommended to remove the high-pass effects, related to noise, by the FFT or take their effects in consideration during interpretation.

\section{Summary and conclusions}

The aeromagnetic data of Galala El Bahariya Plateau are used to detect and locate the edges of the magnetic sources of this area. In order to deduce these sources edges locations and depths, the FFT technique was

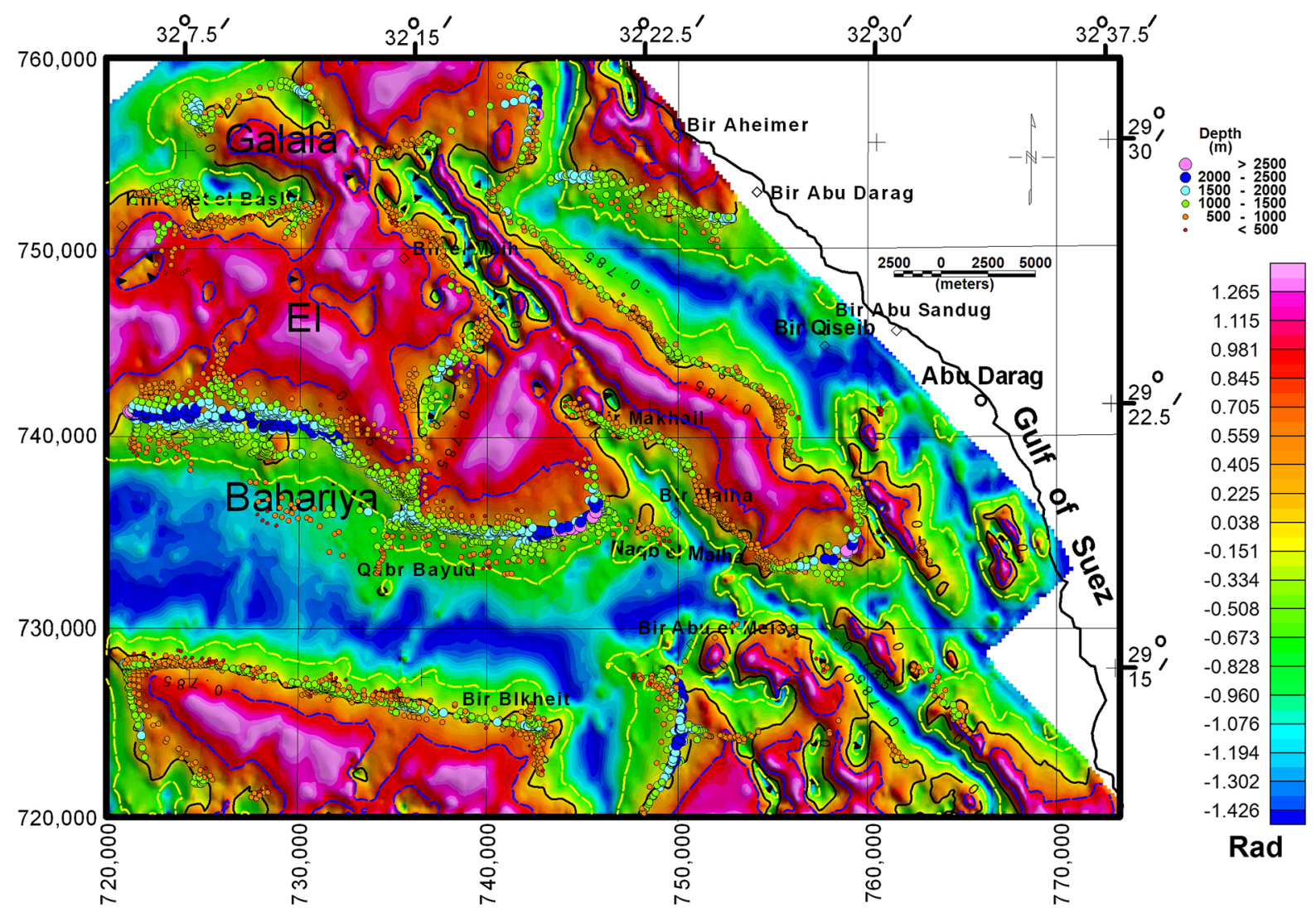

Fig. 9 3D-Euler solutions plotted on Shaded color map of the TDR, Galala El Bahariya Plateau N.B. Euler solutions are located on zero radian contour line of TDR map 

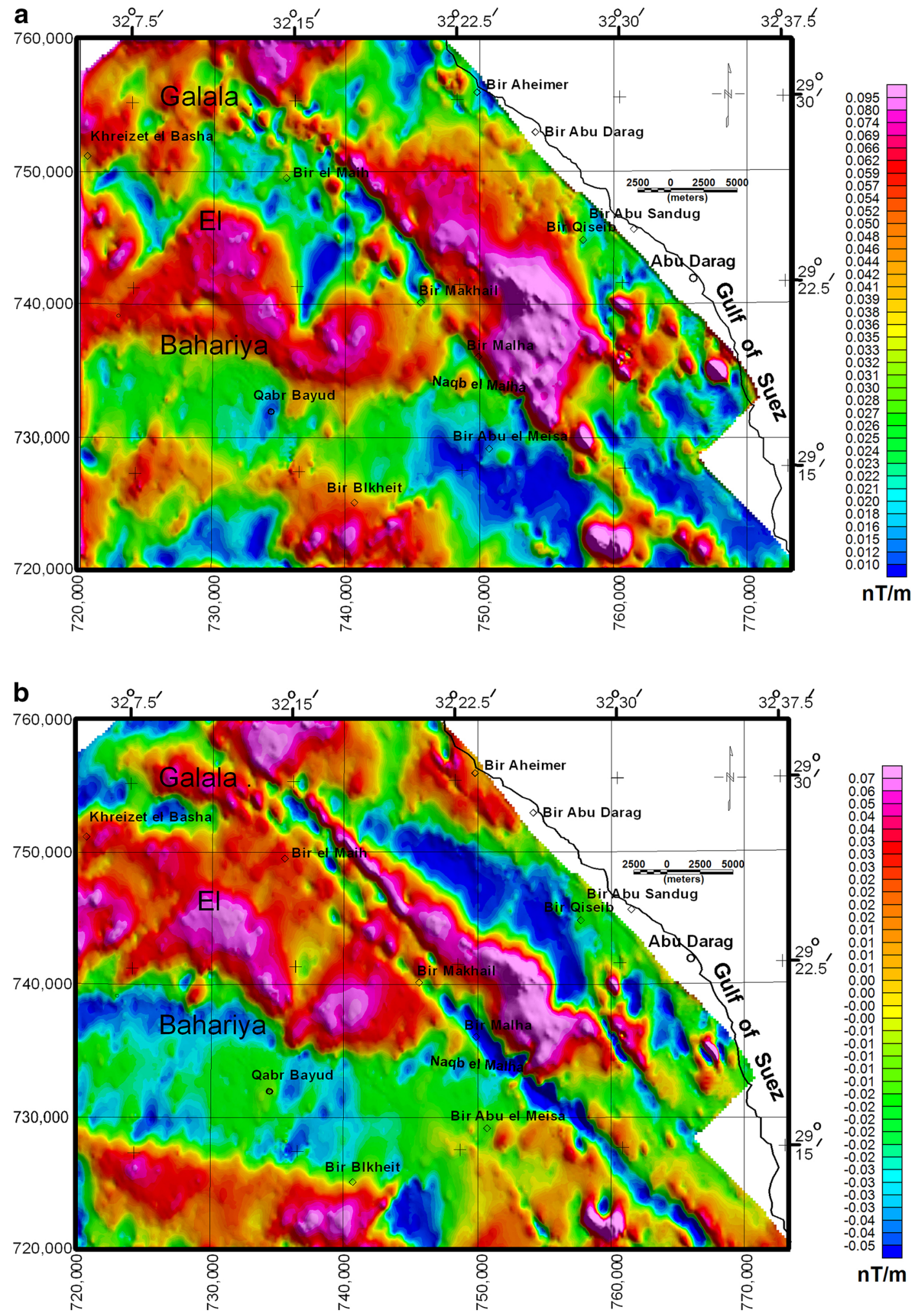

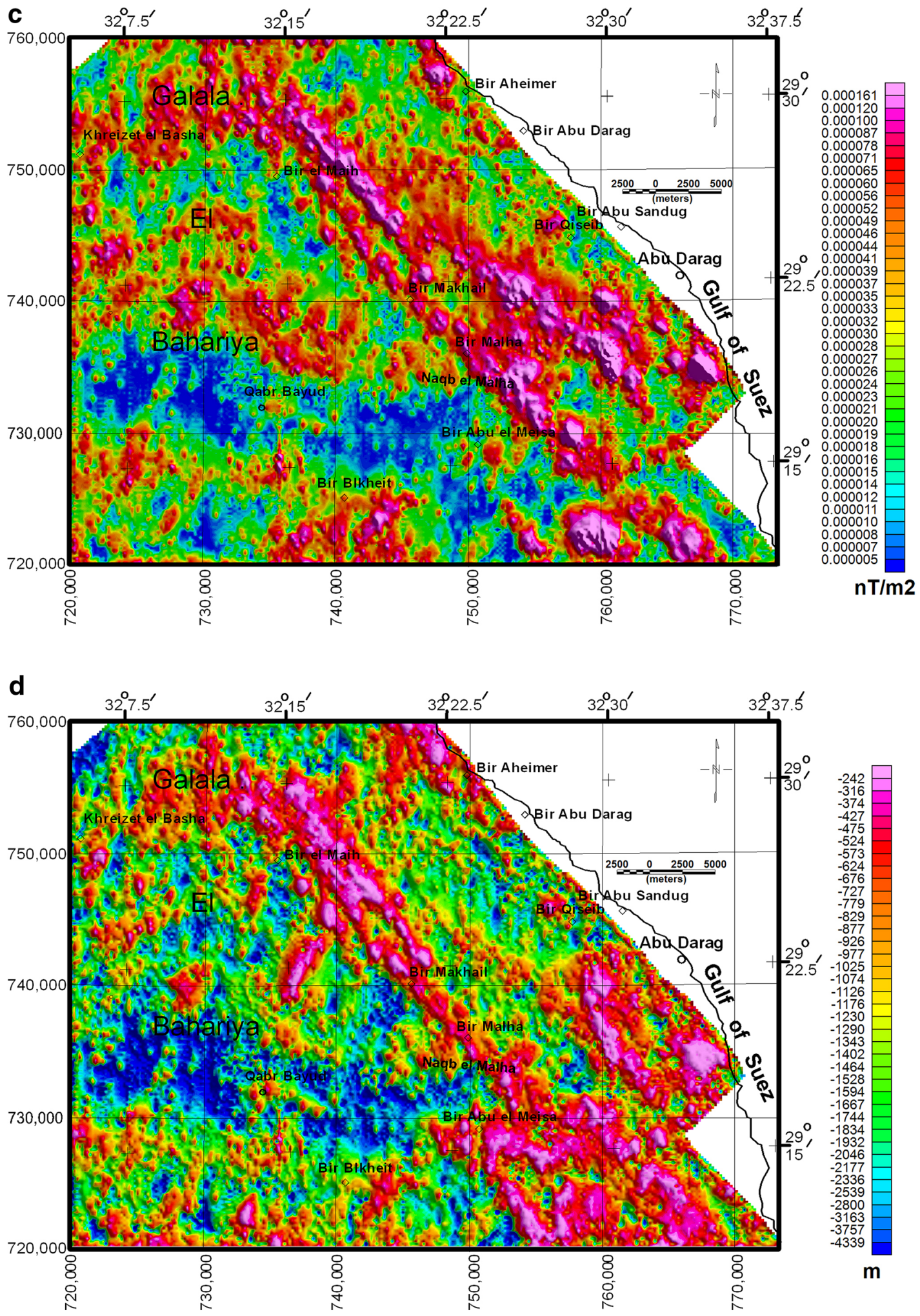

Fig. 10 continued 


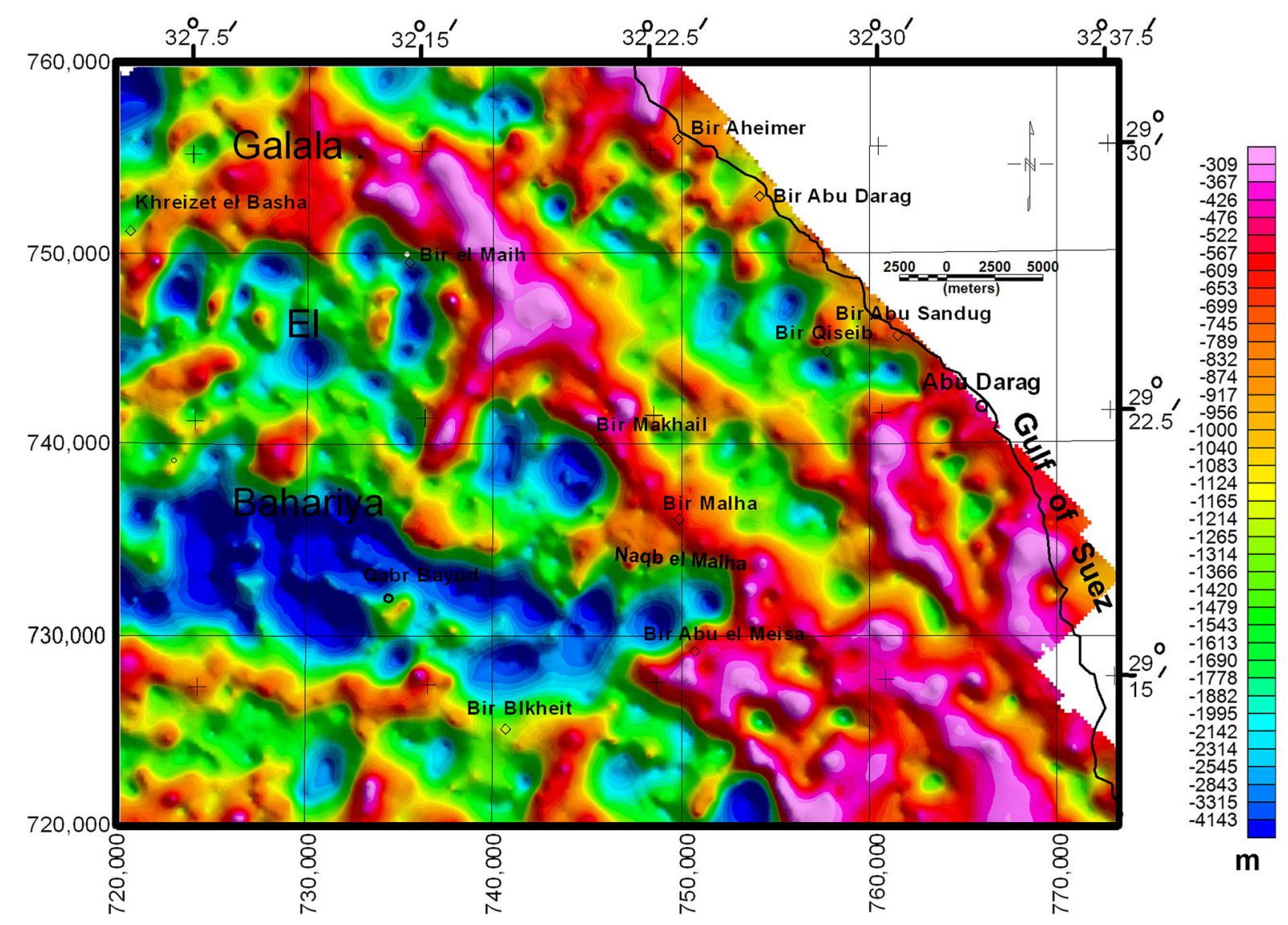

Fig. 11 Depth to magnetic basement as calculated using SPI technique, Galala El Bahariya Plateau

applied to separate the residual components from the regional ones. The regional sources have an average depth of about $3.75 \mathrm{~km}$. whereas; shallow sources show average depth of about $2 \mathrm{~km}$. The regional sources have an elongated structural pattern trending in the E-W direction (Tethyan trend) while residual sources exhibit an obvious NW (Gulf of Suez) trend at the eastern parts of the study area.

The tilt angle derivative (TDR) and its total horizontal derivative (THDR_TDR) were used to locate the edges of these regional and residual sources. Zero contour line of the TDR represents these sources edges. Positive values should be locate above the magnetic sources while negative values are located away from them. The half distance between $\pm \pi / 4$ $( \pm 0.785)$ Radian was used to calculate the depth to these edges. The calculated depth by this method (Salem et al. 2007) changes from few hundreds of meters to about $3000 \mathrm{~m}$. The THDR_TDR map shows these edges as sharper and its values are the reciprocal of the depth to these contacts. The deduced average depths above them vary from about 500 to more than $3000 \mathrm{~m}$. 3D-Euler deconvolution (ED) was carried out on the RTP aeromagnetic data. The suitable depth solutions are derived by using structural index 0 (contact structural index), window size of $15 \times 15$ and grid cell size $300 \mathrm{~m}$. ED is a locator and depth estimator for magnetic contacts under the assumption that the edges of anomalous sources are caused by vertical contacts. Under this assumption, the resulted solutions are plotted on the TDR map. A very well correlation between them was introduced. This correlation is an easiest way to confirm the horizontal location and depth of the edges. Both of TDR and ED show that the area was affected by Gulf of Suez rifting system. This can be noticed by the abundance of the NW trends which related to the Gulf rifting system in the eastern area. The western side was less affected by 
this rifting system where both deep and shallow components preserve its older E-W trend that related to the Tethyan or Mediterranean trend.

Two main techniques were used to calculate the depth to the magnetic basement sources. AS and SPI reflected similar results for estimating the basement depths. Form both of them the depth ranges from 240 to $4340 \mathrm{~m}$.

Finally, the TDR, ED, AS, and SPI techniques attributed to delineate the location and depths for edges of magnetic sources of the Galala El Bahariya Plateau.

\section{References}

Ardestani VE, Motavalli H (2007) Constraints of analytic signal to determine the depth of gravity anomalies. J Earth Space Phys 33:77-83

Arisoy M, Dikmen U (2013) Edge detection of magnetic sources using enhanced total horizontal derivative of the Tilt angle. Bull Earth Sci Appl Res Cent Hacet Univ 34:73-82

Barbosa V, Sliva J, Medeiros W (1999) Stability analysis and improvement of structural index in Euler deconvolution. Geophysics 64:48-60

Bhattacharyya BK (1966) Continuous spectrum of the totalmagnetic field anomaly due to a rectangular prismatic body. Geophysics 31:97-121

Bournas N, Baker HA (2001) Interpretation of magnetic anomalies using the horizontal gradient analytic signal. Ann Geofis 44:506-526

Cooper GRJ (2009) Balancing images of potential field data. Geophysics 74:17-20

Cooper GRJ, Cowan DR (2008) Edge enhancement of potentialfield data using normalized statistics. Geophysics 73:1-4

Durrheim RJ, Cooper GRJ (1998) EULDEP: a program for the Euler deconvolution of magnetic and gravity data. Comput Geosci 24:545-550

EGPC (1983) Aeromagnetic survey of north Eastern Desert and Gulf of Suez, by Western Geophysical Company of America

Fairhead JD, Salem A, Williams S, Samson E (2008) Magnetic interpretation made easy: The tilt-depth-dip- $\Delta \mathrm{k}$ method. In: 2008 annual international meeting expanded abstracts. Society of Exploration Geophysicists, pp 779-783

Geosoft Program (Oasis Montaj) (2007) Geosoft Mapping and Application System. Inc, Suit 500, Richmond St. West Toronto, ON Canada N5SIV6. Users' Manual

Harris E, Jessell, W, Barr T (1996) Analysis of the Euler deconvolution techniques for calculating regional depth to basement in area of complex structures. SEG Ann Intern Meeting

Hinze WJ, Von Frese RRB, Saad AH (2013) Gravity and magnetic exploration principles, practices, and applications. Cambridge University Press, New York
Hsu Sh, Coppens D, Shyu CT (1998) Depth to magnetic source using the generalized analytical signal. Geophysics 63:1947-1957

Klingele EE, Marason L, Kahle HG (1991) Automatic interpretation of gravity gradiometeric data in two dimensions: vertical gradient. Geophys Prosp 39:407-434

Lee YW (1960) Statistical theory of communication. Wiley, New York, pp 1-75

Marason L, Klingele EE (1993) Advantage of using the vertical gradient of gravity for 3-D interpretation. Geophysics 58:349-355

Meshref WM, Abdel-Baki SH, Abdel-Hady HM, Soliman SA (1980) Magnetic trend analysis in the northern part of Arabian Nubian Shield and its tectonic implications. Ann Geol Surv Egypt 10:939-953

Miller HG, Singh V (1994) Potential field tilt-a new concept for location of potential field sources. J Appl Geophys $32: 213-217$

Mocloed IN (1993) 3-D analytic signal in interpretation of total magnetic field data at low magnetic latitudes. Explor Geophys 24:679-688

Moustafa AR, Shaarawy OA (1987) Tectonic setting of the northern Gulf of Suez. Geophys Soc Egypt Bull 5:339-368

Oruc B (2010) Edge detection and depth estimation using a tilt angle map from gravity gradient data of the Kozakl1-Central Anatolia region, Turkey. Pure Appl Geophys. doi:10. 1007/s00024-010-0211-0

Pilkington M, Keating P (2004) Contact mapping from gridded magnetic data: a comparison of techniques. Explor Geophys 35:206-311

Rahman M, Ullah SE (2013) Constrained interpretation of aeromagnetic data using tilt-angle derivatives from northwestern part of Bangladesh. Glob Adv Res J Eng Technol Innov 2:196-204

Rajaram M (2009) What's new in interpretation of magnetic data? GEOHORIZONS, July 2009/50-51

Ravat D (1996) Analysis of the Euler method and its applicability in environmental investigations. J Environ Eng Geophys 1:229-238

Ravat D, Pignatelli A, Nicolosi I, Chiappini M (2007) A study of spectral methods of estimating the depth to the bottom of magnetic sources from near surface magnetic anomaly data. Geophys J Int 169:421-432

Reid AB, Allsop JM, Granser H, Millett AJ, Somerton IW (1990) Magnetic interpretation in three dimensions using Euler deconvolution. Geophysics 55:80-91

Roest WR, Verhoef J, Pilkington M (1992) Magnetic interpretation using the 3-D analytic signal. Geophysics 57:116-125

Ross HE, Blakely RJ, Zoback MD (2006) Testing the use of aeromagnetic data for the determination of Curie depth in California. Geophysics 71:151-159

Said R (1962) The geology of Egypt. Elsevier, Amsterdam

Salako KA (2014) Depth to basement determination using source parameter imaging (SPI) of aeromagnetic data: an application to Upper Benue trough and Borno Basin. Northeast Nigeria. Acad Res Int 5:74-86

Salem A, Williams S, Fairhead J, Ravat D, Smith R (2007) Tiltdepth method: a simple depth estimation method using first-order magnetic derivatives. Lead Edge 26:1502-1505 
Salem A, Williams S, Fairhead D, Smith R, Ravat D (2008) Interpretation of magnetic data using tilt-angle derivatives. Geophysics 73:L1-L10

Shalaby MH (1985) Geology and radioactivity of Wadi Dara area, North Eastern Desert, Egypt. Thesis Ph.D. Alexandria University

Spector A, Grant FS (1970) Statistical models for interpreting aeromagnetic data. Geophysics 35:293-302

Stavrev PY (1997) Euler deconvolution using differential similarity transforms of gravity or magnetic anomalies. Geophys Prospect 45:207-246
Thurston JB, Smith RS (1997) Automatic conversion of magnetic data to depth, dip, and susceptibility contrast using the SPI (TM) method. Geophysics 62:807-813

Verduzco B, Fairhead JD, Green CM, MacKenzie C (2004) New insights into magnetic derivatives for structural mapping. Lead Edge 23:116-119 